\title{
Cracking the India code: Can Swami Vivekananda come to Ikea's rescue
}

\author{
Chandni Mehta
}

PhD Scholar, Faculty of Management Studies, Banasthali Vidyapeeth, Rajasthan, India

*Corresponding Author: Chandni Mehta

Email: chandnimehta01@gmail.com

\begin{abstract}
Acknowledging and adopting cultural diversity is one the of the most important traits of robust organizations who have permeated globally. This stands true for organizations like Google which advocates open access and rights for netizens globally and yet manages to thrive in a controlled economy like China. Still, cultural competence and understanding the environment we work in forms the very crux of survival of multinational organizations. Ikea which has recently started India operations faces this dilemma and cultural competence can become a deciding factor in its successful existence. It is here that Swami Vivekananda can come to its rescue and provide some valuable lessons to Ikea.
\end{abstract}

Keywords: Cultural diversity, Ikea, Diversity, Integration, Retail, India.

\section{Introduction}

Swami Vivekananda (1863-1902) was one of the most influential "Neo-Vedanta" figures in the contemporary Indian society. His Ideas which merged ancient "Vedanta" philosophy with emergent western approach was his single most important contribution towards growth of Indian society.

While management as a discipline of study and research emerged in the $20^{\text {th }}$ century with management thinkers like Peter Drucker, Frederick Taylor and others. It remained in the domain of western thinkers due to spread of modern industrial society in western world. That is the reason no direct theory or framework related to managerial sciences is directly attributed to Vivekananda. Although, he was one of the foremost thinkers in the field of cultural diversity and the idea of Universal brotherhood.

In this paper we will try and apply the $5 \mathrm{C}$ framework to cultural diversity that we have devised using Vivekananda's thoughts and ideas over Ikea. Recently, Ikea started its India operations with its grand entry in Hyderabad after 12-year struggle. ${ }^{1}$

In fact, with its 240 million and burgeoning middle class, India remained the only big market for Ikea to enter globally. But, more importantly will it be able to profitably gain market share in the retail furniture market segment with strong home brands like Home Town (Big Bazar) and Lifestyle and prevalent culture of hiring a furniture maker to do the job. We must note that most of the foreign brands that have set up shops in India have not managed to break the India code. Either, they have not been able to gain respectable market shares or have remained unprofitable. It took more than 10 years for McDonalds to come up with $\mathrm{McVeggie}$ Burger its first serious success and innovation and yet its India operations are today in doldrums. Coke acquired Thums Up, GoldSpot and other local Indian brands from Parle Bisleri Limited to gain access to Indian market and set-up shop here.

This points out to difficulty in understanding Indian market. And central to that is understanding the diversity of India and managing its diverse population. It is very important to find common roots in a country of myriad languages, cultures, religions and regions to achieve success. And maybe that makes Vivekananda far more relevant to us now than 100 years back. He was the first to instill the lessons of Universalism among us, question is can his teachings serve an important lesson for Ikea management team today. Can they learn from 125 years old wisdom of an erudite monk?

\section{Objectives}

To study the impact of cultural diversity for Swedish retailer Ikea which has now entered Indian market.

\section{Materials and Methods}

The Study: This study is descriptive in nature which closely has tracked progress foreign multinational corporations in India and issues they face. Ikea in specific has been tracked on its impact and launch globally and specifically its start in India. Study also reviews various literature pertaining to Vivekananda's philosophy written by several authors down the years.

The Sample: The data reviewed consists of articles, journals, books and literature available on Swami Vivekananda accessed through Open Access in Online, libraries, Ramakrishna Mission and research organizations. Literature has been segregated into the following heads:

1. Collected Works of Swami Vivekananda

2. Indian Thinkers on Swami Vivekananda

3. International Thinkers on Swami Vivekananda

4. Management Thinkers on Swami Vivekananda

\section{Results and Discussions}

Liberalization in 1991 induced rapid development in Indian economy and conversantly it attracted many foreign operators to Indian shores. (Budhwar and Varma, 2010) ${ }^{2}$

And this brought upon a whole new series of problems for these companies. The qualitative information collected from various sources has helped in understanding the challenges faced by various corporations in India. We see a strong correlation in Quantitative indices like Ease of Doing 
Business and the qualitative assessment of difficulties faced in India.

Even access to land, labor and machinery does not guarantees success for them. Majorly, this has been attributed to cultural diversity issues that these organizations have had to manage in India. "And they call for the peculiarities and idiosyncrasies of the Indian workforce and business exigencies, including diversity issues." (Woodard and Saini, 2006) $)^{3}$

\section{How many India exist in our country: One or many?}

It's easy to see why the lure of India is high among any global organization. We are a nation of 1.2 billion and still increasing population. Goods and Sales Tax (GST) a centralized system of taxation introduced on $1^{\text {st }}$ of July 2017 has made us one market but has been on the anvil of introduction for past 4-5 years. On top of it if there's one language that India understands it is English. And there's no dearth of Expats in America or UK who can take hold of the reins in Indian unit. ${ }^{2}$ Still, why do so many foreign MNC's fail here.
Historically, entire India stretching from Kashmir to Kanyakumari has never been under one common governance and rule. Except for British India which in a sense united India for the first time under one common governance model we never had one unified system. After Independence we adopted a Constitution and gave over selves a unified approach. Still, we have incorporated different codes of living like Islamic Sharia Law, Hindu Marriage Act and Special Marriage Act. And that brings us to a major puzzle. What seems like one single market is it really one big market or to be fair collection of disparate many cities, cultures and regions. Is India really one?

Does a common thread exist in Hyderabad, Gurgaon, Bangalore \& Mumbai the four cities where Ikea plans to run stores? From the surface while all of them are home to burgeoning Indian middle class and have been helped by the Indian IT companies to expand to current shape. But, as we delve deeper we seem many differences appearing. Let's consider a short analysis on the cultural and contextual differences among the top cities where Ikea will be present;
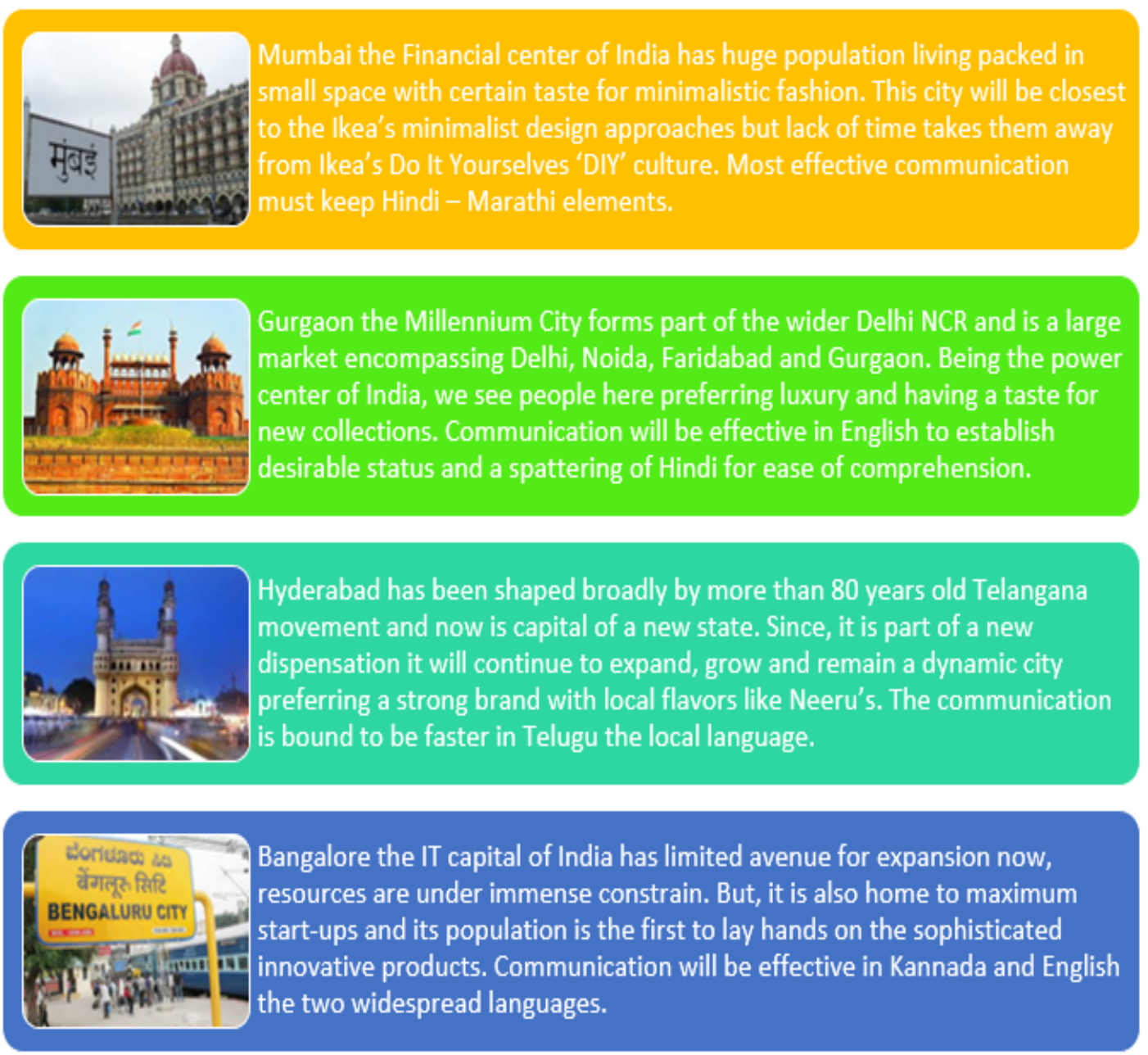

This short analysis shows that each of these cities have their own distinct cultures, values, languages, food and characteristics. Ikea will have to sell to not one but many India's. And thus, as an organization appreciating the strength of cultural diversity through Vivekananda's eyes will prove to be the key to their success.

This cultural integration must be managed in term of local, diverse hiring necessary to connect to the populace 
but also in terms of Branding elements of the stores. From Biryani to Samosas to Vada pav to Vada sambar the Ikea Kitchens will have to embellish local cuisines with high quality in their stores.

\section{C Framework: 125 years old workable wisdom from Vivekananda}

After extensive literature review and analysis of Vivekananda's thoughts we have been able to establish 5 important pillars of cultural competence. When these 5 distinct elements come together, they create a medley of cultural competence and integration of diverse groups, thoughts and ideas. They are;
Commensality: Developing a community that eats together and live together

Communication: Strong and effective communication which must go together with becoming a strong messiah for our Idea

Conflict Management: Managing both Internal and external conflicts which can arise due to difference of opinion between persons and surrounding environment.

Creativity: Discover and synthesize new ideas that can stand test of time and are relevant for future generations

Cohesion: Developing oneness and relations between individuals, groups and units. This cohesion must be achieved with inclusiveness in the society.

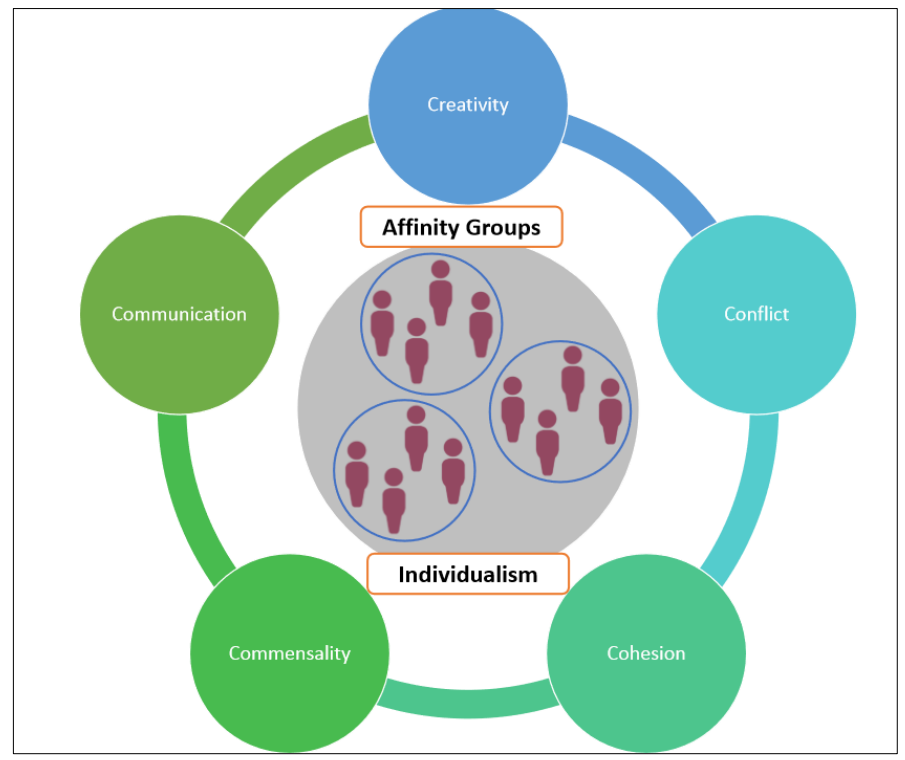

\section{Fig. 1: 5C Framework of cultural diversity}

Applying 5C framework that we have talked about in our paper, Ikea should;

Commensalism: Build one Ikea team with multiple onsite (in each city) and local off sites for the employee branding. Open social communication channels informally for their employees to converse, bond and exchange ideas.

Communication: Keep communication channels filled with local languages and vernacular elements within the common thread of English based communication. Sales persons must use these dialects and words as part of these pitches. Prepare sales training material with diverse languages, local words and regional elements.

Cohesion: Create a One Ikea brand and One Ikea idea. Ikea cherishes and tries to imbue the values its stand for among its employees globally. It must permeate same values in its Indian employees also. One of the important things Ikea vouches for is the 'DIY' culture (Do It Yourself). While it is immensely worked to its advantage in western economies, it's a difficult proposition in Indian culture where we are used to visit family run shops of local furniture walaas and there's no dearth of cheap manual labor in our economy. ${ }^{4}$ Ikea plans to counter this by providing the furniture assembly services to its customers. But, making available external vendors for assembly is one thing, making them vouch for Ikea and let them accept Ikea as their own employer is another thing. That would require use of Cohesion and activities centered around Cohesion across range of its employees both Internal and External.

Conflict Management: We recently came across a customer compliant about presence of caterpillar in Ikea's food in Hyderabad store. ${ }^{5}$ As a result, company withdrew the outsourced food items till it was sure of the highest quality. But, this issue isn't completely done yet. GHMC (Greater Hyderabad Municipal Corporation) have conducted a raid taking cognizance of customers complaint on social media. And notices have been sent to Ikea and its vendor Haldiram's, Nagpur. ${ }^{6}$

But, such issues cannot be completely negated in a country as large as India, they can be minimized with highest levels of Quality control. What its needs to quickly develop are conflict management manuals across products, customer care and services rendered. A lot of products inside Ikea's portfolio will continue to remain outsourced due to cost concerns and 30\% outsourcing norms for foreign single brand retailers. But, Ikea needs to develop robust measures for stringent Quality management (QM). It can 
strategically put high remunerations across Quality Audit (QA) \& QM teams to get the best of talents. This will go a long way in ensuring that Ikea maintains a clear leadership in terms of product quality.

\section{Creativity}

Mcdonald's epitomized creativity in India with its McVeggie Aloo Tikki burger. Similarly, Ikea needs to come up with Indian products or distinct Indian elements in its product portfolio. Can we deliver these distinct Indian elements? We know "Sagwaan" (Teak wood) an India tree wood elucidates an image of sturdy furniture.

Can Ikea add such local elements in its product brochures and display? Can Ikea adapt Neem (Mahogany) based Herbal elements in its furniture which is supposed to be highly resistant to termite? Will we see Sandalwood products (found in India \& Australia only) in its stores and incorporation of ethnic, India designs.

\section{Conclusion}

"Workplaces are in many ways a microcosm of a nation, representing multiple kinds of people based on race, gender, ethnicity, culture, religion, sexual orientation -- all under one banner, working towards the same goal." (Bharadwaj R 2016). ${ }^{7}$ To that extent Ikea did well when it went to China. It adopted innovative price points and did modifications in its product portfolio to get to Chinese customer purses. "But it also faced issues like an embarrassing recall of 1.7 million chests and drawers in China." 8

India can however still $\mathrm{t}$ prove to be a difficult market for Ikea to crack. Unlike China or any other nation that Ikea has every operated in we are a divergent nation of different races, cultures, regions and religions. While western management system talked about concepts of Openness and Universalism since past 30 years or so. We still have erudite leaders and personalities like Swami Vivekananda who have told us about importance of Cultural Integration 125 years back. Ikea will do well to listen to him and adopt Cultural diversity as a way of existence in India. Our 5C Framework provides an important instrument of adopting cultural competence for the retailer and making its chances of success higher.

\section{References}

1. Financial Times (2018) "Ikea unpacks first store in India after 12-year struggle": https://www.ft.com/content/81f6b6fa-9b7811e8-9702-5946bae86e6d (Retrieved at $9^{\text {th }}$ August 2018)

2. Budhwar, P. 2003. "Culture and Management in India" In M. Warner (Ed.) Culture and Management in Asia. London:

Routledge.

3. Woodard, N. and Saini, D.S. (2006), "Diversity management issues in USA and India: some emerging perspectives", in Singh, P., Bhatnagar, J. and Bhandarker, A. (Eds), Future of Work: Mastering Change, Excel Books, New Delhi, pp. 149164. [Google Scholar]

4. Soliman A (2016) "IKEA Expanding into India": https://www.linkedin.com/pulse/ikea-expanding-india-ahmedsoliman (Retrieved on 2nd September 2018)

5. Jayachandran N (2018) "Caterpillar found in Ikea biryani: What can you do if you find an insect in your food.": https://www.thenewsminute.com/article/caterpillar-found-ikeabiryani-what-you-can-do-if-you-find-insect-your-food-87689 (Retrieved at 14th September 2018)

6. The Hindu (2018) "Insect found in food at Ikea": https://www.thehindu.com/news/cities/Hyderabad/insectfound-in-food-at-ikea/article24844539.ece (Retrieved $1^{\text {st }}$ September 2018).

7. Bharadwaj R (2016) "Need for workplace diversity: Challenges in Indian Organizations": India Today: https://www.indiatoday.in/educationtoday/featurephilia/story/workplace-diversity-and-challengesin-india-342395-2016-09-21 (Retrieved 4th September 2018).

8. Narayanan M (2018). "Ikea might face big challenges in India's unique market." Asia Times: http://www.atimes.com/article/ikea-might-face-big-challengesin-indias-unique-market/ (Retrieved $17^{\text {th }}$ September 2018)

How to cite this article: Mehta C. Cracking the India code: Can Swami Vivekananda come to Ikea's rescue. J Manag Res Anal. 2018;5(4):427430. 